\title{
Análisis Multitemporal de los cambios de la vegetación, en la Reserva de Producción de Fauna Chimborazo como consecuencia del cambio climático
}

\section{(Multitemporal Analysis of vegetation change at Chimborazo Reserve as a result of climate change)}

\author{
Pamela A. Paula1, Luis Zambrano², Paulina Paula ${ }^{3}$
}

\begin{abstract}
Resumen:
El cambio climático es una problemática mundial que afecta al estado de conservación de los ecosistemas en todas las regiones del mundo; así como también en la Reserva de Producción de Fauna Chimborazo. Está ligado a las actividades antropogénicas dentro y fuera de la misma como es el pastoreo extensivo e intensivo de ovejas y ganado vacuno que han ocasionado efectos sobre la vegetación y en el suelo dado al consumo de plantas nativas y a todos los procesos del ecosistema por estar relacionados entre sí. La metodología usada para lograr la discriminación óptima del cambio y estado de conservación de la vegetación, se logra a través de la aplicación de imágenes satelitales LANDSAT 5, LANDSAT 7, ortofotos y fotografías aéreas a partir del año 1962 - 1966 hasta el año 2010 distribuidos en tres períodos; empleando procedimientos como la clasificación supervisada y el cálculo del Índice Diferencial Normalizado de Vegetación (NDVI). La actividad antrópica para el período 1962-1966 determina un $0.26 \%$ y la nieve un $10.30 \%$, mientras que para el período $2010-2011$, el porcentaje de intervención se incrementa a un $9.54 \%$ y la nieve decrece a un $4.46 \%$, evidenciándose la pérdida de la nieve perpetua por influencia de la radiación solar.
\end{abstract}

Palabras clave: Imágenes Satelitales; Índice Diferencial Normalizado de Vegetación (NDVI); Clasificación Supervisada; Ecosistemas.

\begin{abstract}
:
Climate change is a global problem that affects the state of conservation of ecosystems in all regions of the world; as well as in the Chimborazo Fauna Production Reserve, which is linked to anthropogenic activities inside and outside it, such as the extensive and intensive grazing of sheep and cattle that have caused effects on vegetation and soil given to the consumption of native plants and all ecosystem processes because they are related to each other. The methodology used to achieve optimal discrimination of vegetation change and conservation status is obtained through the application of satellite images LANDSAT 5, LANDSAT 7, orthophotos and aerial photographs from 1962 to 1966 up to 2010 distributed in three periods; using procedures such as supervised classification and the calculation of the Normalized Differential Index of Vegetation. Anthropogenic activity for the period $1962-1966$ determines $0.26 \%$ and snow is $10.30 \%$, while for the period $2010-2011$, the percentage of intervention increases to $9.54 \%$ and the snow decreases to $4.46 \%$, evidencing the loss of perpetual snow due to solar radiation.
\end{abstract}

Keywords: Satellite images; Normalized Differential Index of Vegetation (NDVI); Supervised Classification; Ecosystems.

\footnotetext{
1 ESPOCH - CENSIG, Riobamba - Ecuador (ppaula@espoch.edu.ec).

2 ESPOCH - CENSIG, Riobamba - Ecuador (luiszzhecho18@gmail.com).

${ }^{3} \mathrm{ESPOCH}$ - FIE, Riobamba - Ecuador (papaula@espoch.edu.ec).
} 


\section{Introducción}

Una de las principales Áreas Protegidas del Ecuador es la Reserva de Producción de Fauna Chimborazo declarada el 26 de octubre de 1987, se ubica en las provincias de Bolívar, Chimborazo y Tungurahua; posee una superficie de 58560 ha de acuerdo con la clasificación que realizó Sierra 1999 (citado por ECOLAP y MAE. 2007). La Reserva presenta formaciones vegetales como bosque siempre verde montano alto, páramo herbáceo, páramo seco y Gelidofitia; así como también formaciones geológicas como el volcán Chimborazo y el volcán Carihuairazo.

Las actividades antropogénicas dentro y fuera de la reserva tales como el pastoreo extensivo e intensivo principalmente de ovejas y ganado vacuno, han ocasionado daños por pisoteo a la vegetación nativa a diferencia de los camélidos por la presencia de una uña en cada falange (en lugar de pezuña) de cada pata y una almohadilla plantar en cada dedo (Wheeler, 1995), que causan un menor daño a la vegetación y al suelo. Otro particular problema presente en la reserva es la quema de pajonal, ya que es una práctica preferida por las 38 comunidades para la obtención de pasto tierno y fresco; indiscutiblemente esta actividad ocasiona pérdida de grandes extensiones de la cobertura vegetal en el Área Protegida.

El 11 de julio de 1964 se pone en vigencia en el Ecuador la primera Ley de Reforma Agraria y Colonización con un nuevo concepto de derecho de accesibilidad a la tenencia de la tierra, es decir la eliminación de los latifundios, las tierras sin ningún uso productivo y los minifundios.

Aplicada la Reforma Agraria hasta 30 años después, los Andes ecuatorianos sufrieron notables transformaciones ocasionando que las actividades agrícolas se expandieran directamente al páramo de la Sierra Central, donde las condiciones ambientales no eran convenientes para cultivos de una sola variedad y su producción fue insuficiente. Por consiguiente en esta zona paulatinamente se da la rotación de cultivos con especial énfasis en el cultivo de papa en asociación con otros. Desde 1964 aumentó la presión demográfica en el campo, la tala del bosque y la ocupación de tierras ociosas, haciendo difícil estimar los cambios ocurridos a través del tiempo (Camacho, 2013).

Ciertamente el uso de herramientas digitales, como ortofotos, fotografías aéreas y las facilitadas por los sensores instalados en satélites que se encuentran orbitando alrededor del planeta, permiten obtener imágenes de la tierra que son la base para analizar temporalmente la vegetación condicionando una secuencia dinámica de niveles jerárquicos que varían a través del tiempo, y con ello conocer los cambios de la zona en estudio que permite determinar las principales causas y efectos, provocados por acciones naturales y antropogénicas. Con la aplicabilidad de estas herramientas se conoce la diversidad de la cobertura vegetal así como el uso de suelo en la Reserva de Producción de Fauna Chimborazo.

Construyendo de esta manera una herramienta de gestión, que permita vincular aquellos factores físicos, climáticos y sociales que de alguna u otra forma han ocasionado cambios notorios en la composición vegetal, y formular alternativas para la conservación de la vegetación como parte de servicios ecosistémicos, generando información que incentive a garantizar la conservación y así la disponibilidad de recursos naturales para las futuras generaciones.

El objetivo alcanzado fue el estudio multitemporal de la cobertura vegetal con el cambio de uso de suelo en la Reserva de Producción de Fauna Chimborazo, determinando los tipos de ecosistemas con la discriminación en las imágenes satelitales, fotografías aéreas de diferentes años, logrando así determinar qué factores incidieron en los cambios de la vegetación de los diferentes años; y poder formular alternativas para la conservación de la vegetación como parte de servicios ecosistémicos; planteándose como hipótesis si "La cobertura vegetal y el uso de suelo no están expuestos a cambios en el transcurso del tiempo" o "La cobertura vegetal y el uso de suelo están expuestos a cambios en el transcurso del tiempo". 


\section{Metodología}

\section{A. Tipos de ecosistemas y de vegetación, a través de imágenes satelitales y fotografías aéreas de diferentes años}

Se recopila información secundaria en las instituciones involucradas en Investigación, Administración y Gestión de la Reserva de Producción de Fauna, como el Ministerio del Ambiente (MAE), Gobierno Autónomo del cantón Guano (GAD Guano), Escuela Superior Politécnica de Chimborazo (ESPOCH), Instituto Geográfico Militar (IGM), Instituto Espacial Ecuatoriano (IEE), Instituto Nacional de Meteorología e Hidrología (INAMHI).

Se elaboró un mapa de vegetación y/o ecosistemas basados en el Sistema de "Clasificación de los Ecosistemas del Ecuador Continental", manejado actualmente por el Ministerio del Ambiente del Ecuador, determinando así los Ecosistemas para la Reserva de Producción de Fauna Chimborazo. Las especificaciones técnicas de la cartografía empleada y generada son: Sistema de Coordenadas Proyectadas UTM Zona 17S, Datum WGS 84.

Una vez obtenidas las fotografías aéreas e imágenes satelitales, se clasificaron en tres diferentes períodos: 1962-1966; 2000 y 2010-2011, las mismas que tuvieron que ser georefenciadas, cortadas y delimitadas.

Para los períodos 1962-1966 y 2000 las imágenes que presentaron menor o ninguna presencia de nubosidad fueron utilizadas, mientras que las imágenes con alta nubosidad tuvieron que ser complementadas con imágenes de otros años; de tal forma se pueda contar con un mosaico de imágenes de la Reserva.

Mediante el montaje del escenario 2010-2011 (más actual a la fecha en ortofotos) y la clasificación de los ecosistemas del Ecuador Continental (MAE, 2013), se genera un shapefile de puntos superpuestos que describan la clasificación ecosistémica y observación directa del mosaico que permite procesar las imágenes de los diferentes períodos por estrato estudiado.

Una de las categorías es "Intervención" que hace referencia a aquellos asentamientos humanos y actividades antrópicas que se deriven de esta última; y la categoría "Otros" hace referencia a las nubes y nieve presentes en las imágenes del área de la Reserva.

Mediante la observación y comparación multitemporal de los períodos estimados, se corrige el archivo shp ${ }^{4}$ con las firmas espectrales.

Se realiza la clasificación supervisada de las imágenes para categorizar la cobertura vegetal, a base de las características de las celdas o pixeles y su similitud para la definición de las clases siguiendo las metodologías propuestas (Arango, 2015).

Se construyen los escenarios de cambios de los diferentes períodos de estudio, cuantificando la superficie por categoría descrita por el "Sistema de Clasificación de los Ecosistemas del Ecuador Continental" (MAE, 2013), al igual las categorías "Intervención, Nieve y Otros"; los ecosistemas fueron correlacionados en orden cronológico en función de los periodos: 1962-1966, 2000 y 2010-2011; los mismos que fueron correlacionados con una inspección de campo y constatación de los ecosistemas de la Reserva que fueron determinados a través de la clasificación supervisada.

\section{B. Factores que han incidido en los cambios de vegetación en los diferentes años}

Se analizó la relación histórica de los últimos 60 años mediante la recopilación de información secundaria, donde se estudiaron aquellos aspectos biofísicos, demográficos, socioeconómicos, políticos, ambientales que han incidido directa o indirectamente a través

\footnotetext{
${ }^{4}$ shp. Archivo shapefile de tipo puntos, es un formato de archivo informático propietario de datos espaciales desarrollado por la compañía ESRI.
} 
del tiempo en la estructura ecosistémica de la Reserva de Producción de Fauna Chimborazo. (INGTELSIG, 2010).

Se calculó el Índice de la Diferencia Normalizada de la Vegetación de la Reserva de los últimos 30 años (1987; 2000; 2015), con imágenes Landsat 7, Landsat 5 y Landsat 8 del portal web de la U.S Geological Survey (USGS).

Las imágenes fueron seleccionadas bajo los siguientes parámetros: calidad visual, mínima presencia del porcentaje de nubes para el área estudiada, años particulares de interés y sin presencia de bandas sin información. Se tomó una imagen capturada en el año 1987 debido a la presencia excesiva de nubes en las imágenes disponibles de los años 1985 y 1986 para el área estudiada.

Para el cálculo del NDVI en imágenes Landsat 7 y Landsat 5 se empleó la Ecuación 1.

$\mathrm{NDVI}=\frac{\text { banda } 4 \text {-banda } 3}{\text { banda } 4+\text { banda } 3}$

Para el cálculo del NDVI en imágenes Landsat 8 se empleó la Ecuación 2.

DVI $=\frac{\text { banda } 5 \text {-banda } 4}{\text { banda } 5 \text { +banda } 4}$

Para determinar los factores que han incidido en los cambios de vegetación en los diferentes años, se comprobó el estado de conservación de la vegetación, mediante la generación del Índice de Vegetación Normalizada (NDVI) según lo propuesto por Gilabert et al (1997), para los años 1987; 2000; 2015, determinando así el estado y evolución de la vegetación de la reserva en los últimos 29 años; estos resultados fueron respaldados a través de análisis del cambio de uso del suelo y los correspondientes datos climáticos (precipitación y temperatura) de las estaciones meteorológicas más cercanas al Área Protegida.

Para la interpretación del NDVI de cada período, se usó la Tabla 1 de interpretación, basada en la tabla de índices de vegetación de Merg, C. et al (2011).

Tabla 1. Rangos establecidos para la interpretación del NVDI.

\begin{tabular}{|c|c|}
\hline Rango & Interpretación \\
\hline$-0,3$ a 0 & Suelo desnudo, agua, roca o nieve \\
\hline $0,01-0,1$ & Vegetación Dispersa (Poca Vegetación) \\
\hline $0,11-0,2$ & Vegetación moderada (Arbustos, Prados) \\
\hline $0,21-0,4$ & Páramo (Húmedo) \\
\hline $0,41-1$ & Vegetación densa o vigorosa (Alta Humedad) \\
\hline
\end{tabular}

\section{Resultados y discusión}

\section{A. Tipos de ecosistemas y de vegetación, a través de imágenes satelitales y fotografías aéreas de diferentes años}

Para los tres períodos estudiados, se basó en la clasificación ecosistémica publicada por el Ministerio de Ambiente al año 2016 en la que se clasifican en: Arbustal siempreverde y Herbazal del Páramo, Bosque siempreverde del Páramo, Herbazal del Páramo, Herbazal húmedo montano alto superior del Páramo, Herbazal húmedo subnival del Páramo, Herbazal inundable del Páramo, Herbazal ultrahúmedo subnival del Páramo, Herbazal y Arbustal siempre verde subnival del Páramo, Intervención, Nieve y Otros. De las imágenes satelitales se determinan las firmas espectrales en los tres períodos, de tal forma que se identifica la similitud a lo largo del tiempo. Esto no significa que esta zona no ha variado en el tiempo, al contrario nos permite contrastar las modificaciones que ha sufrido en cuanto a la extensión de la cobertura presente en cada período.

Como se puede observar en las figuras 1, 2 y 3, la Clasificación Ecosistémica se mantiene, pero difiere en la extensión territorial. 


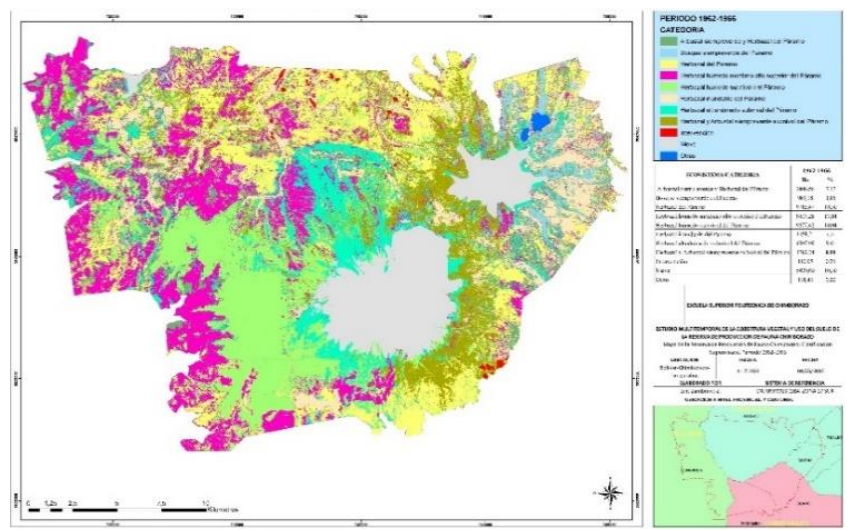

Figura 1. Clasificación Ecosistémica, período 1962 - 1966 RPFCH.

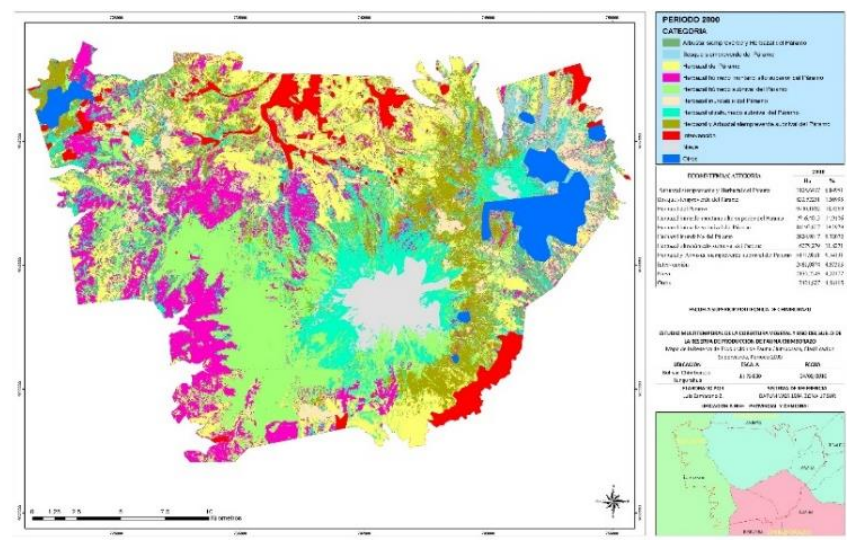

Figura 2. Clasificación Ecosistémica, período 2000 RPFCH.
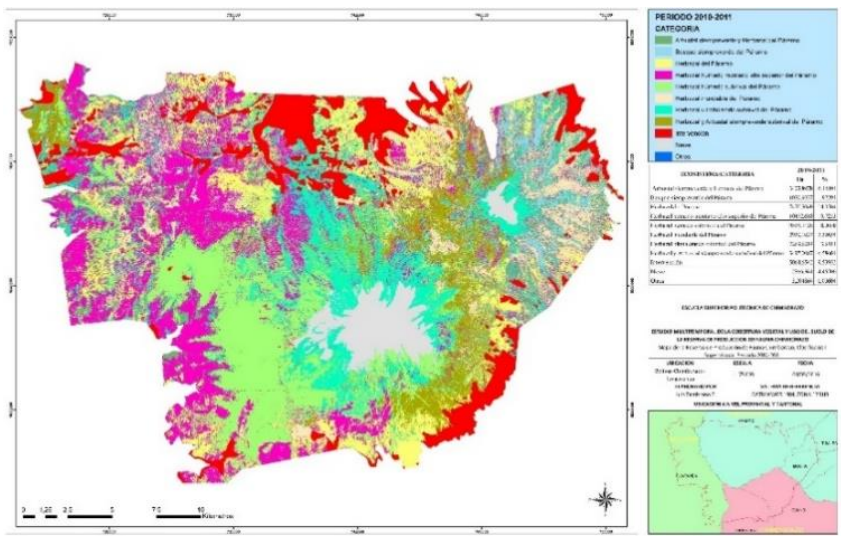

Figura 3. Clasificación Ecosistémica, período 2010 - 2011 RPFCH.

Al comparar las figuras 1 y 3 , se observa que la categoría Nieve disminuye notablemente en esta transición de tiempo, es decir que en 49 años se ha reducido un $5,84 \%$ de la superficie ocupada, y se incrementa notablemente la categoría de Intervención llegando a ocupar un $9.54 \%$ del área de la Reserva de Producción de Fauna Chimborazo, como se muestra en la Tabla 2.

B. Construcción y clasificación supervisada de los períodos 1962-1966; 2000; 20102011

En la Tabla 2 y Figura 4, se muestran los cambios ocurridos de la cobertura ecosistémica en la Reserva de Chimborazo. 
Tabla 2. Ecosistemas de la RPFCH, periodos 1962-1966; 2000; 2010-2011.

\begin{tabular}{|c|c|c|c|c|c|c|c|}
\hline \multirow[t]{2}{*}{ Ecosistema } & \multirow[t]{2}{*}{ Código } & \multicolumn{2}{|c|}{$1962-1966$} & \multicolumn{2}{|c|}{2000} & \multicolumn{2}{|c|}{$2010-2011$} \\
\hline & & ha & $\%$ & ha & $\%$ & ha & $\%$ \\
\hline $\begin{array}{c}\text { Arbustal } \\
\text { siempreverde y } \\
\text { Herbazal del } \\
\text { Páramo } \\
\end{array}$ & AsSn01 & 3806,56 & 7,17 & 3105,65 & 5,85 & 3423,9 & 6,45 \\
\hline $\begin{array}{c}\text { Bosque } \\
\text { siempreverde } \\
\text { del Páramo }\end{array}$ & BsSn01 & 989,18 & 1,86 & 833,52 & 1,57 & 1020,93 & 1,92 \\
\hline $\begin{array}{l}\text { Herbazal del } \\
\text { Páramo }\end{array}$ & HsSn02 & 9715,47 & 18,30 & 9730,19 & 18,33 & 7470,31 & 14,07 \\
\hline $\begin{array}{c}\text { Herbazal } \\
\text { húmedo } \\
\text { montano alto } \\
\text { superior del } \\
\text { Páramo }\end{array}$ & $\mathrm{HsSn03}$ & 9473,28 & 17,84 & 7916,4 & 14,91 & 10472,62 & 19,73 \\
\hline $\begin{array}{l}\text { Herbazal } \\
\text { húmedo } \\
\text { subnival del } \\
\text { Páramo }\end{array}$ & $\mathrm{HsNn01}$ & 9577,42 & 18,04 & 10192,62 & 19,20 & 9559,71 & 18,01 \\
\hline $\begin{array}{c}\text { Herbazal } \\
\text { inundable del } \\
\text { Páramo }\end{array}$ & HsSn04 & 4091,21 & 7,71 & 2824,9 & 5,32 & 2950,1 & 5,56 \\
\hline $\begin{array}{c}\text { Herbazal } \\
\text { ultrahúmedo } \\
\text { subnival del } \\
\text { Páramo }\end{array}$ & $\mathrm{HsNn02}$ & 4997,99 & 9,41 & 6279,28 & 11,83 & 7263,62 & 13,68 \\
\hline $\begin{array}{l}\text { Herbazal y } \\
\text { Arbustal } \\
\text { siempre verde } \\
\text { subnival del } \\
\text { Páramo }\end{array}$ & $\mathrm{HsNn03}$ & 4712,24 & 8,88 & 5171,9 & 9,74 & 3497,01 & 6,59 \\
\hline Intervención & Inter01 & 140,05 & 0,26 & 2481,09 & 4,67 & 5064,65 & 9,54 \\
\hline Nieve & Niev01 & 5470,6 & 10,30 & 2135,25 & 4,02 & 2366,36 & 4,46 \\
\hline Otros & OA01 & 118,43 & 0,22 & 2421,63 & 4,56 & 3,2 & 0,01 \\
\hline TOTAL & & 53092,43 & 100 & 53092,43 & 100 & 53092,41 & 100 \\
\hline
\end{tabular}

La categoría "Intervención" presenta el mayor incremento con un 9,28\%, equivalente a 4 924,6 hectáreas; pues en el primer período (años 1962-1966) se cuantificó apenas un 0,26\%; para el segundo período (año 2000) aumentó a 4,67\%; sin embargo, para el tercer período evaluado (años 2010-2011) el porcentaje crece a 9,54\%; hay que aclarar que esta categoría es una de las más importantes en cuestión de superficie ocupada, la misma que posiblemente fue generada por el cambio de uso del suelo, producto de actividades antrópicas. Le sigue el ecosistema "Herbazal ultrahúmedo subnival del Páramo", que para el período 1962-1966 presenta un 9,41\%, subiendo un $2 \%$ para el período 2000 con $11,83 \%$ y para en el período $2010-2011$, registra un $13,68 \%$; mostrando un incremento de $4,27 \%$ equivalente a 2265,63 hectáreas. El ecosistema "Herbazal húmedo montano alto superior del Páramo" en el período 1962-1966 presenta un 17,84\%, para el período 20102011 se incrementa obteniendo un 19,73\%, correspondiéndole un aumento del 1,89\% (999,34 hectáreas). El ecosistema "Bosque siempre verde del Páramo" presenta el menor incremento de superficie debido a que en el primer período se cuantificó en 1,86\%, y en el tercer periodo este porcentaje presentó $1,92 \%$, evidenciando un ligero aumento de $0,06 \%$ $(31,75$ hectáreas). Claramente la categoría "Nieve" presenta la mayor disminución de superficie, debido a que en el primer período (años 1962-1966) se cuantificó un 10,30\%, en el segundo período (años 2000) baja a 4,02\%, y en el tercer periodo (años 2010-2011) llega a 4,46\%, indicando una reducción de 5,85\% equivalente a 3 104,24 ha, evidenciando 
la variabilidad climática que ha experimentado el Área Protegida. Le sigue el "Herbazal del Páramo", registrando para los años 1962-1966 un 18,30\%; sin embargo, para los años 2010-2011, se evidencia un decrecimiento del $4,23 \%$, Ilegando al $14,07 \%$ que equivale a 2245,16 hectáreas. El "Herbazal y Arbustal siempre verde subnival del Páramo", en el primer período (años 1962-1966) se cuantifica un 8,88\%, sin embargo, para el tercer período (años 2010-2011), disminuye al 6,59\%, experimentando un decrecimiento del 2,29 $\%$ equivalente a 1215,23 hectáreas. Esta tendencia de reducción superficial, experimenta también el "Herbazal inundable del Páramo", en el primer período (años 1962-1966) se cuantifica un $7,71 \%$, sin embargo, para el segundo período (años 2000) disminuye al $5,32 \%$, para que en el tercer período evaluado (años 2010-2011), se establezca en un $5,56 \%$, evidenciando un decrecimiento correspondiente a $2,15 \%$ (1 141,11ha). La categoría "Arbustal siempre verde y Herbazal del Páramo" en el primer período demuestra un 7,17\%, sin embargo, para el tercer período disminuyó a 6,45\%, observándose un decrecimiento del $0,72 \%$ (382,66 ha). El "herbazal húmedo subnival del Páramo", en el primer período registró un $18,04 \%$ y en el tercer período alcanza un $18,01 \%$, presentando la menor disminución correspondiente a 0,03\% equivalente a 17,71 hectáreas.

Los cambios analizados en los ecosistemas presentes en la Reserva de Producción de Fauna Chimborazo se deberían a la influencia del cambio climático pues según Cáceres (2001), la región interandina posee tendencia a la desertificación y cambios ecosistémicos, debido a los cambios de temperatura cada vez más extremos que incidirían notablemente en la frágil estabilidad de las formaciones vegetales andinas.

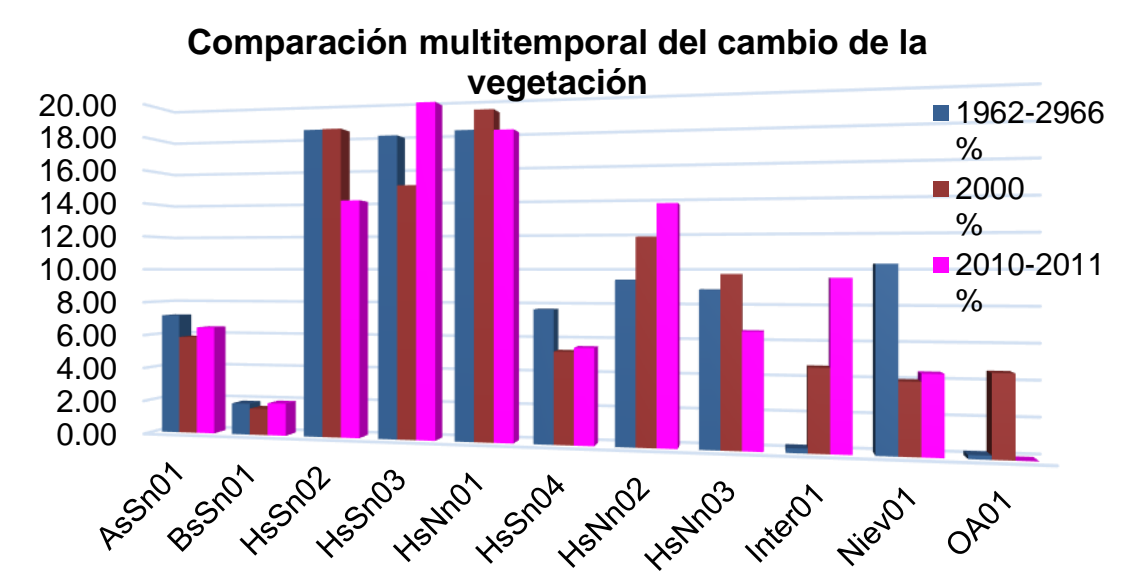

Figura 4. Ecosistemas de la RPFCH, Períodos 1962-1966; 2000; 2010-2011.

\section{Factores que han incidido en los cambios de vegetación en los diferentes años}

La alteración de la cobertura vegetal en la Reserva se ve afectada por el pastoreo principalmente por el de ovejas y ganado vacuno, a esto se suma la quema de pajonal, mecanismo por el cual las comunidades obtiene pasto fresco y tierno; las quemas y el ganado son las principales causas que caracterizan a la presencia humana dentro de la reserva. El $80 \%$ de la Reserva es propiedad de 38 comunidades indígenas, organizaciones campesinas y propietarios privados. El cambio climático, por los cambios de temperatura cada vez más extremos, sería un factor que afectaría a la frágil estabilidad de las formaciones vegetales andinas.

De acuerdo con la Figura 5, se observa que en el año 1987 el $26.61 \%$ de la superficie de la Reserva presentaba suelo desnudo, agua, roca o nieve; el $18.40 \%$ coincidían suelos con vegetación dispersa (poca vegetación); el $14.30 \%$ corresponde a suelos con vegetación moderada (arbustos, prados); el 28.62\% limitan suelos de páramo (húmedo) y el $12.06 \%$, vegetación densa o vigorosa (alta humedad). 
De acuerdo al INAMHI ${ }^{5}$ (Anuario, 1987) en este año existió una precipitación promedio anual de $624.36 \mathrm{~mm}$.

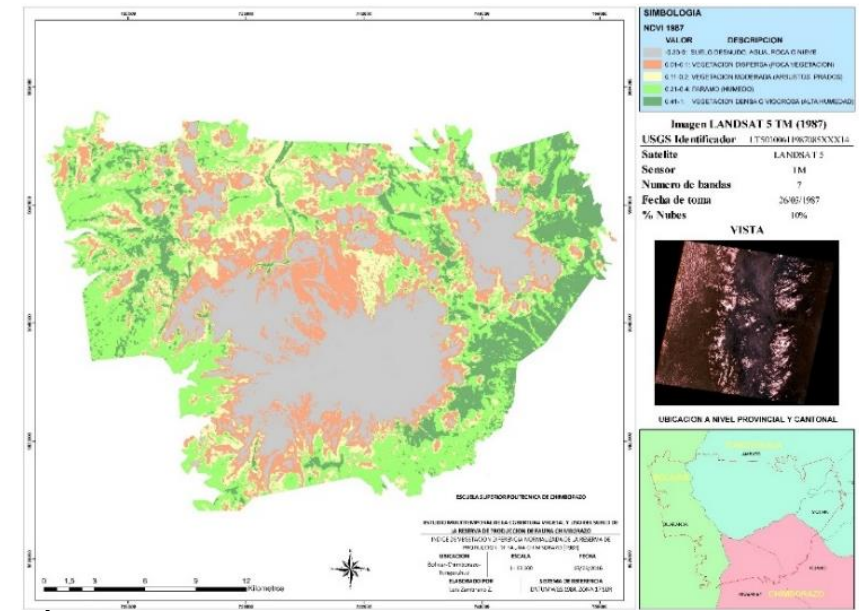

Figura 5. Índice de Vegetación Diferencia Normalizada, RPFCH (1987).

El análisis del Índice de Vegetación (Figura 6), demostró que para el año 2000 el $27,50 \%$ de la superficie de la Reserva presentaba suelos desnudos, agua, roca o nieve; el $15,90 \%$ le corresponde a suelos con vegetación dispersa (poca vegetación); el 19,22\% de la superficie equivale a suelos con vegetación moderada (arbustos, prados); el 32,51\% de la superficie a suelos de páramo (húmedo) y el 4,87\% a vegetación densa o vigorosa (alta humedad). Comparando con el año 1987 que registró un valor del 26,61\% de suelo desnudo se incrementa al 27,50 \% (año 2000), esto indica que la superficie con ninguna vegetación fue en aumento; para el caso de los suelos con vegetación dispersa en el año de 1987 registró un $18,40 \%$ y en el año 2000 registra un $15,90 \%$ denunciando pérdida de la cobertura con vegetación dispersa; en el año 2000 los suelos con vegetación moderada presentan un $19,22 \%$ mostrando un aumento positivo con respecto al $14,30 \%$ evidenciado para el año1987. El páramo presentó en el año 2000 un porcentaje superficial de 32,51\%, esto revela que existió un crecimiento positivo para esta cobertura con respecto al año 1987; en el año 2000 la vegetación densa o vigorosa se cuantifico en un 4,87\% revelando un estado de conservación bajo con respecto al 12,06\% visible en el año de 1987. Durante ese año la precipitación anual oscilaba entre los 500 y 1250 mm de precipitación anual.

El análisis del Índice de Vegetación (Figura 7), se evidencia que para el año 2015 el $2,31 \%$ de la superficie de la Reserva presentaba suelo desnudo, agua, rocas o nieve; el $30,82 \%$, coincidían con suelos con vegetación dispersa (poca vegetación); el 31,99\% de la superficie suelos con vegetación moderada (arbustos, prados); el 31,09\% condicionan suelos de páramo (húmedo), mientras aquellos suelos con vegetación densa o vigorosa (alta humedad) para este año, disminuyó a 3,79\%. La superficie correspondiente al suelo desnudo o sin vegetación mostró la mayor reducción para el año 2015 a un 2.31\%; sin embargo, es importante mencionar que en el año de 1987 cubría el $26,61 \%$ y en el año 2000 se incrementa al $27.50 \%$. Los suelos con vegetación densa o vigorosa (alta humedad) presentaron una menor reducción en el porcentaje de cobertura, pues en 1987 cubrían un 12,06\% de la Reserva, en el año 2000 la cobertura desciende al 4,87\% y en el 2015 estos suelos de vegetación densa se reducen al 3,79\%.

\footnotetext{
${ }^{5}$ Instituto Nacional de Meteorología e Hidrología.
} 


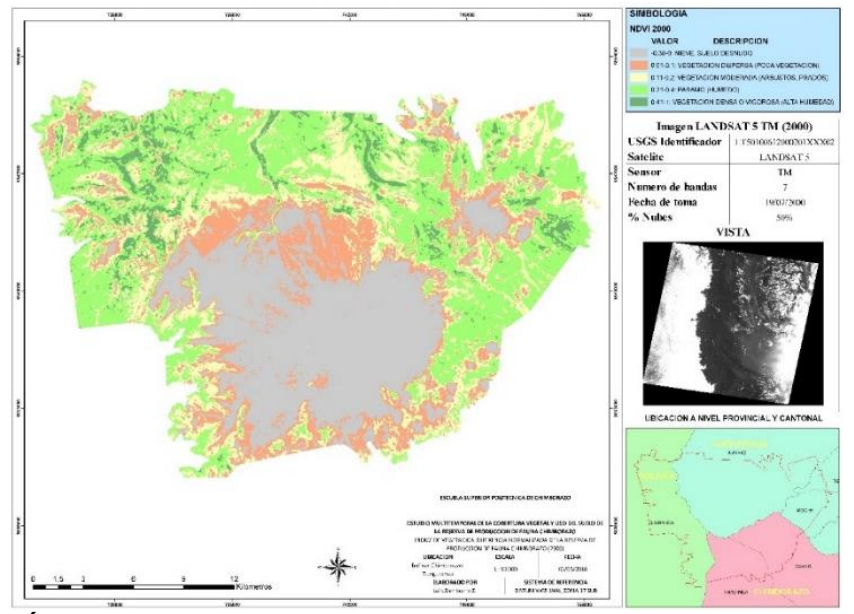

Figura 6. Índice de Vegetación Diferencia Normalizada, RPFCH (2000).

Los suelos con vegetación moderada (arbustos, prados), muestran el mayor incremento en el porcentaje de cobertura, debido a que en el año 1987 registra un porcentaje superficial de $14,30 \%$, mientras que para el año 2000 este porcentaje sube a 19,22\%, para finalmente en el año 2015 llegar a 31,99\%, demostrando que este tipo de cobertura predomina en la Reserva actualmente; así mismo los suelos con vegetación dispersa (poca vegetación) manifestaron una tendencia similar; en el año 1987 mostraron un $18,40 \%$ y un $15.90 \%$ en el año 2000 , mientras que para el año 2015 la superficie se incrementó al 30,82\%. La cobertura vegetal páramo (húmedo) presentó el menor cambio en el período de tiempo evaluado, puesto que para el año 1987 muestra un 28,62\% de la superficie de la Reserva, este porcentaje para el año 2000 se elevó a 32,51\%, y en el año 2015 se redujo sutilmente a $31,09 \%$.

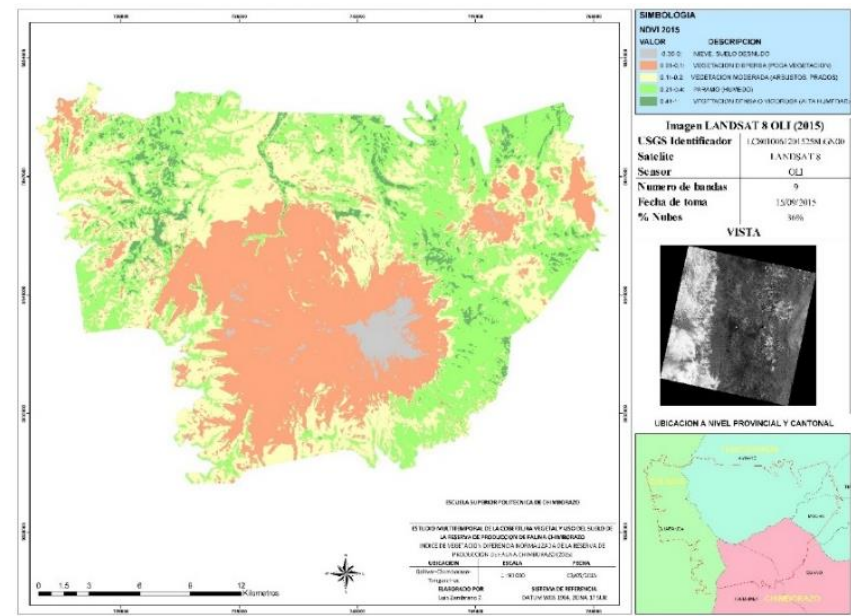

Figura 7. Índice de Vegetación Diferencia Normalizada, RPFCH (2015).

Mediante el análisis porcentual del comportamiento vegetal resultante del $\mathrm{NDVI}^{6}$ de los años 1987, 2000 y 2015, la Reserva de Producción de Fauna Chimborazo, mostró cambios en su estructura vegetal ( Tabla 3), la superficie correspondiente al suelo desnudo o sin vegetación mostró la mayor reducción, pues en 1987 cubría el $26,61 \%$ de la superficie de la $\mathrm{RPFCH}^{7}$ y en el año 2015 este valor se redujo a 2,31\%; mientras que aquellos suelos con vegetación densa o vigorosa (alta humedad) presentaron una menor reducción en el porcentaje de cobertura, pues en 1987 cubrían un 12,06\% de la Reserva, en el año 2000

6 Índice Diferencial Normalizado de Vegetación.

${ }^{7}$ Reserva de Producción de Fauna Chimborazo. 
la cobertura disminuye al 4,87\% y en el 2015 estos suelos se reducen al 3,79\%. Los suelos con vegetación moderada (arbustos, prados), muestran el mayor incremento en el porcentaje de cobertura, debido a que en el año 1987 registra un porcentaje superficial de 14,30\% y para el año 2000 este porcentaje sube a 19,22\%, que finalmente en el año 2015 llegan a incrementarse al 31,99\%, demostrando que este tipo de cobertura es la que predomina en la Reserva. Asimismo, los suelos con vegetación dispersa (poca vegetación) mostraron una tendencia similar; en el año 1987 poseían un $18,40 \%$, mientras que para el año 2015 la superficie se incrementó al 30,82\%. La cobertura vegetal páramo (húmedo) presentó el menor cambio en el período evaluado, puesto que para 1987 muestra un $28,62 \%$ de la superficie de la Reserva, este porcentaje para el año 2000 se elevó al $32,51 \%$, y en 2015 se redujo levemente a $31,09 \%$.

Tabla 3. Dinámica Porcentual del NDVI en los años 1987; 2000 y 2015.

\begin{tabular}{|c|c|c|c|c|c|c|}
\hline $\begin{array}{c}\text { Rango } \\
\text { s NDVI }\end{array}$ & Año & $\begin{array}{c}\text { \%Suelo } \\
\text { desnudo, } \\
\text { agua, roca o } \\
\text { nieve } \\
\mathbf{- 0 , 3 - 0}\end{array}$ & $\begin{array}{c}\text { \% Vegetación } \\
\text { Dispersa } \\
\text { (Poca } \\
\text { Vegetación) } \\
\mathbf{0 , 0 1 - 0 , 1}\end{array}$ & $\begin{array}{c}\text { \% Vegetación } \\
\text { moderada } \\
\text { (Arbustos, } \\
\text { Prados) } \\
\mathbf{0 , 1 1 - 0 , 2}\end{array}$ & $\begin{array}{c}\text { \% } \\
\text { Páramo } \\
\text { (Húmedo } \\
\text { ) }\end{array}$ & $\begin{array}{c}\text { \% Vegetación } \\
\text { densa o } \\
\text { vigorosa (Alta } \\
\text { Humedad) } \\
\mathbf{0 , 4 1 - 1}\end{array}$ \\
\hline $\begin{array}{c}-0,31- \\
0,72\end{array}$ & 1987 & 26,61 & 18,40 & 14,30 & 28,62 & 12,06 \\
\hline $\begin{array}{c}-0,46- \\
0,65\end{array}$ & 2000 & 27,50 & 15,90 & 19,22 & 32,51 & 4,87 \\
\hline $\begin{array}{c}-0,33- \\
0,58\end{array}$ & 2015 & 2,31 & 30,82 & 31,99 & 31,09 & 3,79 \\
\hline Diferencia (\%) & $\mathbf{- 2 4 , 3 0}$ & $\mathbf{1 2 , 4 2}$ & $\mathbf{1 7 , 7 0}$ & $\mathbf{2 , 4 7}$ & $\mathbf{- 8 , 2 7}$ \\
\hline $\begin{array}{c}\text { Diferencia } \\
\text { (ha) }\end{array}$ & $\mathbf{- 1 2 9 0 3 , 9 5}$ & $\mathbf{6 5 9 3 , 1 8}$ & $\mathbf{9 3 9 5 , 3 4}$ & $\mathbf{1 3 1 0 , 4 8}$ & $\mathbf{- 4 3 9 2 , 0 2}$ \\
\hline
\end{tabular}

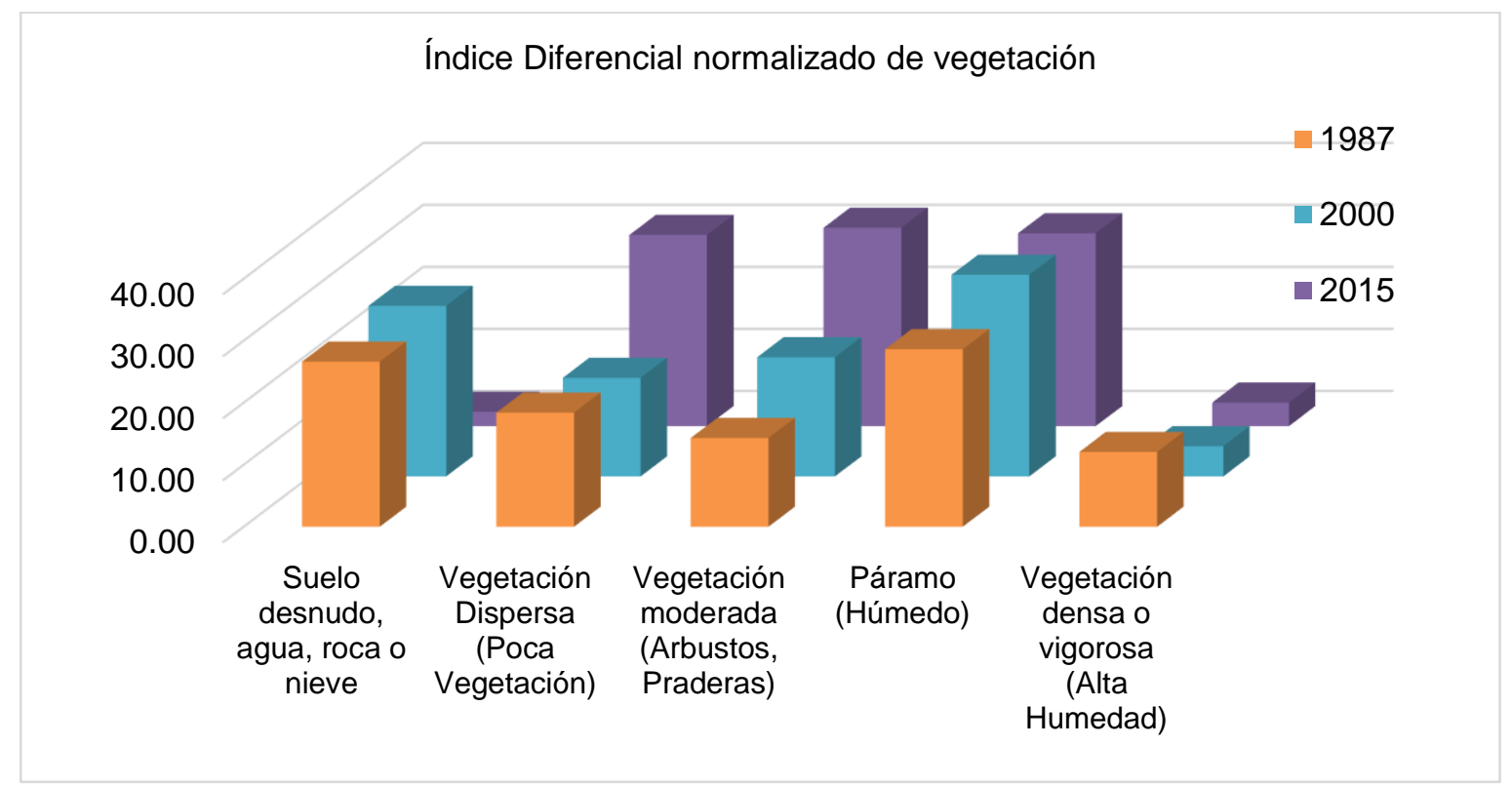

Figura 8. NDVI de los años 1987,2000 y 2015.

De acuerdo con el análisis particular de la nieve perpetua (Tabla 4), se evidencia una notoria disminución de esta categoría, hasta llegar a una reducción de la superficie cubierta del $46.17 \%$ 
Tabla 4. Superficie de nieve perpetua.

\begin{tabular}{|c|c|c|c|}
\hline Años & Superficie ha & $\%$ & Años Transcurridos \\
\hline 1979 & 1717,82 & 100,00 & 0 \\
\hline 2001 & 1038,16 & 60,43 & 22 \\
\hline 2015 & 924,77 & 53,83 & 36 \\
\hline
\end{tabular}

\section{Conclusiones y recomendaciones}

Se determinó que la categoría Intervención dentro de la RPFCH, aumentó considerablemente durante los períodos 1962-1966 (0,26\%) y 2000 (4,67\%), duplicándose para el período $2010-2011$ (9,54\%) de 140,05 ha (0,26\%) en el período 1962-1966, crece a 4924,6 (9,28\%) en el período 2010-2011; mayoritariamente esta superficie la cubren suelos agrícolas, de ganadería y repoblaciones forestales exóticas, así como el establecimiento de comunas en sitios específicos alterando la composición de los frágiles ecosistemas de la Reserva.

El ecosistema Bosque Siempre Verde del páramo tiene el menor incremento de superficie, presentando un aumento de $0,06 \%$ (31,75 hectáreas) con respecto al período 1962-1966.

La categoría Nieve, mostró la mayor disminución de superficie indicando una reducción de 5,84\% equivalente a 3104,24 ha, evidenciando la variabilidad climática que ha experimentado el área protegida.

El ecosistema Herbazal Húmedo Subnival del Páramo, presentó la menor disminución correspondiente a 0,03\% equivalente a 17,71 hectáreas.

Los factores que han incidido en los cambios de vegetación en los diferentes años son: colonización del ecosistema páramo, ley de reforma agraria (1964), 38 comunidades que habitan dentro de la Reserva, introducción de camélidos andinos cuya población crece, actividades agropecuarias en territorio de la Reserva y el cambio climático.

Según Arteaga (2014) el resultado del NDVI calculado está entre $-1,0$ y 1,0 que básicamente representan el verdor y donde cualquier valor negativo corresponde principalmente a las nubes, el agua y la nieve y los valores cercanos a cero corresponden principalmente a las rocas y al terreno desnudo. Los valores muy bajos de NDVI (por debajo de 0,1$)$ corresponden a áreas yermas de rocas, arena o nieve. Los valores moderados representan terrenos con arbustos y prados $(0,2$ a 0,3$)$, mientras que los valores altos indican bosques de zonas templadas y tropicales $(0,6$ a 0,8$)$. De acuerdo con la estadística de los resultados obtenidos del Índice Diferencial Normalizado de Vegetación se observa como valores mínimos $-0,31 ;-0,46,-0,33 ;$ y como valores máximos 0,$72 ; 0,65 ; 0,58$ respectivamente de los años 1987, 2000 y 2015; lo que significa que, en el estado de conservación de la vegetación para la producción fotosintética y alopatía de la vegetación, se concluye que se evidencia una alteración ecosistémica.

Para este estudio se establecen los siguientes rangos: $-0,33$ a $0 ; 0,01$ a 0,$1 ; 0,11$ a 0,$2 ; 0,21$ a 0,$4 ; 0,41$ a 0,72; que permitieron discriminar de mejor manera la vegetación y su estado; logrando así determinar 5 clases: suelo desnudo, agua, roca o nieve; vegetación dispersa (poca vegetación), vegetación moderada (arbustos, prados), páramo (húmedo); vegetación densa o vigorosa (alta humedad); de los cuales se observa que para el año 2015 existe un porcentual bastante marcado en lo que respecta a la vegetación moderada se incrementa en $17,70 \%$ al igual que la vegetación dispersa se incrementa en un $12,42 \%$ y mientras decrece la vegetación vigorosa en un $8,27 \%$, indicando el evidente cambio ecosistémico que ha experimentado la reserva los últimos 28 años.

El fortalecimiento de las actividades productivas agropecuarias fuera de la Reserva y las actividades ecoturísticas dentro de la misma podrían disminuir la presión sobre su territorio, disminuyendo de esta manera el cambio de uso de suelo.

La Implementación de un sistemas de monitoreo permitirá canalizar acciones que garanticen la conservación del Herbazal inundable de Páramo, que por su fragilidad ha sido sujeto de un acelerado deterioro. 
El resultado del análisis multitemporal, permite aseverar que la cobertura vegetal y el uso de suelo están expuestos a cambios en el transcurso del tiempo, como lo es la influencia del cambio climático que incide directamente en la modificaciones de las precipitaciones y temperaturas como se evidencia que para el año 1987 la precipitación fue de $624,36 \mathrm{~mm}$ anuales, y que para los años subsiguientes disminuye y se incrementa porque existe una oscilación entre $500 \mathrm{~mm}$ a $1250 \mathrm{~mm}$ anuales, y finalmente para el año 2015 registra una precipitación de $492.3 \mathrm{~mm}$ anuales. Otra evidencia es la disminución de la nieve perpetua, huella evidencia en las imágenes satelitales Landsat: L8, L7, L1 de los años 1979, 2001 y 2015; tomando como referencia el año 1979 de partida, se identifica una disminución aproximada del $53.83 \%$ en el transcurso de 36 años.

\section{Bibliografía}

Arango M., Branch J., Botero, V. (2005). Clasificación no supervisada de coberturas vegetales sobre imágenes digitales de sensores remotos: "LANDSAT ETM+". Universidad Nacional de Colombia, Sede Medellín. Facultad de Minas. A. 1027. Medellín, Colombia. PG. 2622.

Arteaga A. (2014). El índice Diferencial de Vegetación Normalizado. GISGEEK. Veracruz. Beltrán, K; Bustamante, M; Albán, M y Argüello, M. (Eds.). (2011). Los páramos de Chimborazo. Un estudio socio-ambiental para la toma de decisiones Gobierno Autónomo Descentralizado de Chimborazo/EcoCiencia/CONDESAN/Programa BioAndes/Proyecto Páramo Andino. Quito.

CANADA CENTRE FOR REMOTE SENSING. (2001). News and announcements. Recuperado de www.ccrs.nrcan.gc.ca (accedido 15/11/ 2015).

ECOLAP y MAE. (2007). Guía del Patrimonio de Áreas Naturales Protegidas del Ecuador. ECOFUND, FAN, DarwinNet, IGM. Quito, Ecuador. P. 152-156.

Holdridge, L. (2000). Ecología basada en zonas de vida. 4a reimpresión. San José, Costa Rica. Instituto Interamericano de Cooperación para la Agricultura. 216 p. Recuperado de

https://books.google.com.ec/books?id=m3Vm2TCjM_MC\&printsec=frontcover\&soe= gbs_ge_summary_r\&cad=0\#v=0nepage $\& q=40 \% 25 \& \bar{f}=$ false (accedido 09/01/2016).

INAMHI. (2009). El cambio climático en el Ecuador. Revista del Instituto Nacional de Meteorología e Hidrología. Quito. Ecuador.

INGTELSIG (2010). Metodología para el mapeo de los Tipos de Bosque y Análisis Multitemporal de sus cambios. CCAD - GTZ. Honduras.

Meneses-Tovar, C.L. (2011). El índice normalizado diferencial de la vegetación como indicador de la degradación del bosque. Comisión Nacional Forestal de México. Vol. 62. Pg. 40-46. Recuperado de http://www.fao.org/3/ai2560s/i2560s07.pdf (accedido 05/01/2016)

MINISTERIO DEL AMBIENTE. (2012). Estrategia Nacional de Cambio Climático del Ecuador 2012-2025. República del Ecuador.

MINISTERIO DEL AMBIENTE DEL ECUADOR. (2013). Sistema de Clasificación de los Ecosistemas del Ecuador Continental. Subsecretaría de Patrimonio Natural. Quito.

Muñoz A. P, (2015), Índices de Vegetación, Geógrafo, CIREN. Recuperado de: http://agroclimatico.minagri.gob.cl/wpcontent/uploads/sites/26/2015/05/Indices-devegetaci\%C3\%B3n-PedroMu\%C3\%B1oz.pdf (accedido 05/01/2016).

Tiedemann, J. L, Zerda, H. R. (2008). Relación Temporal NDVI-PRECIPITACIÓN del Bosque y Pastizal Natural de Santiago del Estero, Argentina. Universidad Nacional de Santiago del Estero. Facultad de Ciencias Forestales. Av. Belgrano 1912. (cp 4200). Santiago del Estero. Argentina. Volumen 14 №3. Pg. 497.

Wasserstrom, R; Southgate, D. (2013). Deforestación, reforma agraria y desarrollo petrolero en Ecuador, 1964-1994, Natural Resources, 4, 34-44 doi:10.4236/nr.2013. 41004. Recuperado de http://www.scirp.org/journal/nr (accedido 05/01/2016). 
Yánez, P; Núñez, M; Carrera, F; Martínez, C. (2011). Posibles efectos del cambio climático global en zonas silvestres protegidas de la zona andina de Ecuador. La Granja. Vol. 13(1): 24-44. ISSN: 1390-3799. Recuperado de http://revistas.ups.edu.ec/index.php /granja/article/view/449/306 (accedido 05/01/2016). 